\title{
Princípio de paridade participativa, reconhecimento e desigualdade social em Território Rural no Bico do Papagaio (TO)
}

\section{Principle of participatory parity, recognition and social inequality in Rural Territory of the Bico do Papagaio (TO)}

Alex Pižzio - Doutor em Ciências Sociais Atualmente é professor no Programa de Pós-Graduação em Desenvolvimento Regional e no Curso de História na Universidade Federal do Tocantins, Palmas-TO.4. E-mail: alexpizzio@gmail.com

Lucélia Neves Santos - Mestre em Desenvolvimento Regional pela Universidade Federal do Tocantins (UFT); pesquisadora no Núcleo de Pesquisa em Desenvolvimento Regional - NPDR. E-mail: luceliadr@gmail.com

\section{Resumo}

O objetivo deste artigo é contribuir ao entendimento das nuances que envolve a questão da desigualdade social, fundamentalmente, no que diz respeito à legitimidade discursiva dos atores na esfera pública. Enquanto base teórica conceitual o artigo recorre à categoria reconhecimento e ao princípio de paridade participativa como apresentados nas formulações pós-critica desenvolvidas por Nancy Fraser. Como base empírica o artigo é um recorte dentro de uma pesquisa realizada com Quebradeiras de coco babaçu, onde se busca analisar a estruturação desta cadeia produtiva a partir das ações do Programa de Desenvolvimento Sustentável do Território do Bico do Papagaio - TO. A análise da participação destes atores na interação com o Estado e o mercado, tem indicado que a categoria reconhecimento constitui-se em elemento chave ao não estabelecimento da paridade participativa e assinala que o não reconhecimento intersubjetivo aumenta o nível de desigualdade social a partir do estabelecimento de um status de inferioridade constituindo-se em um importante limitador da expansão e consolidação da democracia.

\section{Palavras-chave}

Reconhecimento. Paridade Participativa. Quebradeiras de coco babaçu.

\begin{abstract}
The aim of this paper is to contribute to the understanding of the nuances surrounding the issue of social inequality, essentially regarding the legitimacy of discursive actors in the public sphere - While theoretically based conceptual article draws on category recognition and the principle of participatory parity as shown in the postcritical formulations developed by Nancy Fraser - As empirical article is a clipping in a survey of babassu nut breakers, which seeks to analyze the structure of this production chain from the actions of the Programme for Sustainable Development of the Territory of the Parrot's Beak - TO. The analysis of the participation of these actors in interaction with the state and the market, has indicated that the category recognition is a key element in the non-establishment of participatory parity and points out that no intersubjective recognition increases the level of social inequality from the establishment of a status of inferiority thus becoming a major limiting the expansion and consolidation of democracy .
\end{abstract}

\section{Keywords}

Recognition. Participatory Parity. Babaçu nut breakers. 


\section{INTRODUÇÃO}

No Brasil, o fenômeno da desigualdade social surge como um componente da nossa questão social a perdurar desde os tempos do período colonial. A temática tem sido recorrente em diversos estudos nas ciências sociais e, não raro, sua ocorrência tem sido tematizada em associação com a realidade dos trabalhadores. As análises têm se orientado por vieses específicos de cada área, cada qual acentuando mais um ponto ou outro e compondo um cenário geral que, embora divergente em alguns aspectos, em geral, apresentam um sentimento de perplexidade diante de uma realidade marcada por enormes disparidades em termos sociais.

Não somos um país pobre, mas desigual e com um número expressivo de pessoas pobres. O país apresenta um enorme potencial em termos de desenvolvimento econômico, entretanto, ainda enfrenta sérios desafios no que diz respeito às demandas por redistribuição e reconhecimento. O Brasil possui uma das maiores populações do mundo e sua economia ostenta uma posição de destaque em nível mundial, no entanto, ocupa apenas a $73^{a}$ posiçãono ranking do Índice de Desenvolvimento Humano (IDH), segundo os dados do relatório elaborado pela Programa para as Nações Unidas (PNUD, 2010). Apesar de ser um país que vem inovando em termos de políticas sociais de redistribuição e justiça social, apresenta, não obstante, um grande número de pessoas que continuam a enfrentar grandes dificuldades para o exercício dacidadania.

Ao retratar este cenário desconcertante, surgem as múltiplas dificuldades enfrentadas pelos trabalhadores nas diversas regiões do país. Dentre as questões mais frequentes podemos destacar o desemprego, a informalidade, a falta de proteção social, a baixa renda média real, a discriminação por sexo, idade e raça, dentre outros. Todos estes fatores, quando considerados em conjunto, configuram uma realidade social complexa e de difícil diagnóstico. Tal embate, quando teorizado no âmbito da justiça social e da consolidação da democracia, indica a necessidade de articulação de ações tanto no âmbito da redistribuição quanto no âmbito do reconhecimento. As evidências de tal contexto sobre a teoria social "são visíveis na importância que o conceito de reconhecimento vem ganhando nas últimas décadas, seja na filosofia e na ciência política, na sociologia e nos estudos culturais, seja ainda no direito" (NEVES, 2005, p. 81).

Nesta perspectiva, entende-se que a desigualdade é consequência de uma série de desajustes e que seu aparecimento não decorre apenas da ordem econômica (mesmo considerando-se a importância que essa dimensão possui), mas entende-se que ela tem uma origem multidimensional e conflituosa.

Novos Cadernos NAEA, v. 16, n. 1, Suplemento, p. 261-280, jun. 2013 


\section{DESIGUALDADE E JUSTIÇA SOCIAL PERSPECTIVAS TEÓRICAS}

$\mathrm{Na}$ atualidade, o debate sobre situações de justiça social tem ganhado novos contornos com a polêmica entre a necessidade de conciliar ações de redistribuição e reconhecimento. Neste sentido, vários autores, a partir de concepções distintas, vêm tentando lidar com o problema da relação entre redistribuição e reconhecimento, "buscando estabelecer uma posição crítica em relação às lutas sociais contemporâneas, teorizar o lugar da cultura no capitalismo e pensar padrões de justiça" (SILVA, 2005, p. 4). Nancy Fraser (2001) principais expoentes deste debate, tem apontado para a necessidade de se conceber as dimensões da redistribuição e do reconhecimento de forma conjunta e complementar. Segundo Krischke (2003, p. 2), “a distinção entre reconhecimento e redistribuição é apenas uma distinção analítica ou conceitual, com vistas a uma melhor compreensão do alcance das políticas sociais do governo e dos seus efeitos na legitimidade e governabilidade".

Para Taylor (1998), a exigência de reconhecimento adquire premência, pois, o reconhecimento incorreto dos outros pode conduzir uma pessoa ou grupo de pessoas a serem prejudicadas, sendo alvo de uma distorção, quando eles refletem uma imagem limitativa, de inferioridade ou de desprezo deles mesmos. A premissa que está por trás desta exigência é a de que os grupos dominantes consolidam sua hegemonia inculcando uma imagem de inferioridade nos grupos subjugados. Nessa perspectiva, o reconhecimento torna-se fundamental na medida em que a modernidade, por meio do individualismo e do igualitarismo que a caracterizam, cria a expectativa de que todos podem aspirar a igual reconhecimento por parte da sociedade e do Estado.

Nancy Fraser tem contribuído de forma significativa para a discussão em torno do tema reconhecimento, de tal modo, que seu debate com Axel Honneth tem ganhado destaque no meio intelectual. Autora comprometida com a questão da justiça social, inova ao vincular reconhecimento e redistribuição como dimensões que se condicionam mutuamente.

Em "Da redistribuição ao reconhecimento? Dilemas da justiça na era póssocialista" (FRASER, 2001), a autora faz um diagnóstico dos conflitos políticos do final do século XX, chamando a atenção para a mudança paradigmática na agenda dos movimentos sociais que conduziu a um deslocamento das demandas por redistribuição para a emergência de lutas por reconhecimento. Partindo de uma definição de justiça social que requer tanto reconhecimento quanto redistribuição, ela elabora uma tipologia dos movimentos sociais que ajuda a ilustrar sua tese da irredutibilidade entre as duas categorias. 
Sua tipologia consiste na formulação de um modelo bidimensional construído a partir de tipos puros. Nesta direção, devemos imaginar um espectro conceitual de tipos diferentes de coletividades sociais, onde num extremo estão os modos de coletividade que se ajustam aos modelos redistributivos de justiça e, noutro extremo, estão os modos de coletividades relacionados aos modelos de reconhecimento. Esse procedimento permite a autora classificar os movimentos sociais segundo suas demandas na relação redistribuição/reconhecimento.

Gostaria de iniciar pelo aspecto da redistribuição, aqui a autora estabelece um tipo ideal de coletividade cuja existência esteja ligada à economia política. Desse modo, "a raiz da injustiça será a má distribuição socioeconômica e qualquer injustiça cultural adicional derivará em última instância da raiz econômica" (FRASER, 2001, p. 254). Desta forma, o remédio requerido para reparar essa injustiça será a redistribuição político-econômica, em oposição ao reconhecimento cultural. Nesse quadro, considerando, para fins heurísticos, a classe operária explorada assume o modelo de tipo ideal.

Seguindo os mesmos critérios podemos colocar na outra ponta do espectro um tipo ideal de coletividade que se ajuste ao modelo de reconhecimento da justiça. Uma coletividade deste tipo deve estar totalmente enraizada na cultura e não na economia-política. Assim, cabe destacar que estas coletividades são diferenciadas devido a padrões sociais dominantes e não pela divisão social do trabalho. Desse modo, "qualquer injustiça que seus integrantes sofram estará em última instância vinculada à estrutura cultural-valorativa. Dessa forma, a raiz da injustiça será o não reconhecimento cultural, enquanto qualquer injustiça econômica adicional derivará da raiz cultural" (FRASER, 2001, p. 257). Aqui, o movimento GLBT assume o caráter de tipo ideal.

Desse modo, quando lidamos com coletividades que se aproximam da classe operária explorada os remédios são redistributivos. Quando lidamos com coletividades que se aproximam do tipo ideal da sexualidade menosprezada, as injustiças requerem ações no âmbito do reconhecimento. Assim, no primeiro caso, a lógica é de homogeneizar os grupos. No segundo, a lógica é valorizar a peculiaridade do grupo reconhecendo sua especificidade. Ou seja, os remédios redistributivos e de reconhecimento apontam para lógicas opostas. Esta constatação é relevante, pois, como demonstra Fraser (2001) existem coletividades ambivalentes, que demandam simultaneamente por remédios de redistribuição e reconhecimento.

As coletividades formadas por identificação de gênero e raça, por exemplo, são ambivalentes paradigmáticas. Na perspectiva da autora, embora cada uma tenha peculiaridades não compartilhadas pela outra, ambas englobam dimensões 
político-econômicas e culturais-valorativas. Pelo fato de sofrerem injustiças socioeconômicas e de não reconhecimento simultaneamente, nem remédios redistributivos, nem remédios de reconhecimento são suficientes isoladamente. Coletividades ambivalentes necessitam de ambos (FRASER, 2001, p.259).

Ao falar da justiça social, o objetivo de Fraser (2001; 2002) é o de mostrar que tanto as injustiças formadoras das desigualdades econômicas, quanto as injustiças do não reconhecimento, são impedimentos à participação plena na esfera pública. Neste caso, o problema reside em encontrar soluções que contemplem ambos os níveis da justiça, de maneira que não haja uma substituição de um nível por outro.

Pode-se dizer, então, que sem o estabelecimento da igualdade em seus vários níveis, não há uma participação que se dê, de fato, entre iguais. O reconhecimento torna-se, portanto, "um meio de superar as formas de subordinação que são institucionalizadas, ao invés de, simplesmente valorizar um grupo excluído" (OGANDO; ASSIS, 2006, p. 2). Tendo como ponto de partida as formulações apresentadas acima, Fraser (2001) postula a formulação de um principio normativo que inclua ambas reivindicações sem reduzir umas às outras. Desta forma, propõe o princípio da paridade de participação, segundo o qual, a justiça requer arranjos sociais que permitam a todos os membros da sociedade interagir entre si como pares. São necessárias, contudo, duas condições para que a paridade participativa seja possível. Primeiro, deve haver uma distribuição de recursos materiais que garantam a independência e a "voz" dos participantes. Esta condição impede a existência de formas e níveis de dependência e desigualdade econômicas que constituem obstáculos à paridade de participação. Segundo, a paridade participativa requer que os padrões institucionalizados de valor cultural exprimam igual respeito por todos os participantes e garantam iguais oportunidades, com o objetivo de alcançar a consideração social.

Com base no debate teórico acima, pode-se dizer que no plano da formulação das políticas públicas de redistribuição e reconhecimento, estudos como os de Krischke (2003; 2004) têm apontado para o caráter de vanguarda da política social no Brasil ${ }^{1}$, no intuito de aproximar ambas as dimensões. Neste sentido, parece haver uma convergência entre a constatação de Krischke e a de Aldaiza Sposati (2004). Esta última tem defendido a intersetorialidade na formulação das políticas públicas. O saldo da discussão empreendida até o momento indica que tanto as demandas por redistribuição como por reconhecimento passam pela negociação na esfera pública, onde irão adquirir legitimidade através de um mútuo reconhecimento, como acima indicado.

Esta qualificação como de vanguarda é destacada tendo como referencial as políticas implantadas no Governo Lula. 
E aqui, Habermas (1984) tem logrado demonstrar a presença de uma dimensão interativa nas sociedades contemporâneas, de forma que a esfera pública surge como uma espécie de caixa de ressonância das demandas provocadas pelos indivíduos na esfera privada, e que são trazidas ao espaço público diretamente ou através de interlocutores. Neste sentido, o autor tem insistido no papel fundamental das associações e organizações livres que formam a sociedade civil para a teoria democrática deliberativa, pois, estas associações e atores têm vOZ ativa no processo argumentativo no mundo da vida. Cabe aos atores da sociedade civil, nesse modelo discursivo de democracia, um duplo papel: de um lado, eles são responsáveis pela preservação e ampliação da infraestrutura comunicativa próprias do mundo da vida e pela produção de microesferas públicas associadas à vida cotidiana. Ao mesmo tempo, tais atores canalizam os problemas tematizados na vida cotidiana para a esfera pública, tratando de apresentar novas contribuições e soluções de problemas. Entretanto, esta visão idealizada da esfera pública que encontramos em Habermas, onde a negociação no espaço público se pauta pelo melhor argumento, não se confirma na prática.

A esfera pública como tal é ocupada por atores diversos e potencialmente atravessada por instituições como o Estado e o Mercado. Quando consideramos a dinâmica e a importância dos processos participativos na construção de consensos e na formulação de agendas que venham a se tornar públicas e objeto de consideração por parte do Estado, não podemos deixar de considerar que as mesmas são frutos de debate entre interesses diferenciados e que os mesmos encontram-se muitas vezes condicionados por fatores externos. Neste sentido, há sempre uma conjuntura expressa através de uma correlação de forças que congrega necessidades, interesses políticos, interesses do mercado e interesses privados. A equação, quando posta desta maneira, apresenta um resultado que nem sempre é o do melhor argumento.

Nesse momento, gostaríamos de introduzir nesta discussão as formulações de Charles Taylor, pois, suas considerações podem ser conectadas tanto ao pensamento de Fraser, quanto de Habermas.

Charles Taylor (2000) tem enfatizado o caráter de urgência que a categoria reconhecimento tem assumido na sociedade contemporânea. Essa importância ganha relevo dado ao vinculo existente entre reconhecimento e identidade, onde a identidade designa algo como a compreensão de quem somos, de nossas características definidoras fundamentais como seres humanos. Sua tese aqui é que nossa identidade é moldada em parte pelo reconhecimento ou por sua ausência, de tal forma que uma pessoa ou grupo pode sofrer danos reais ou uma real distorção caso a sociedade da qual faz parte lhe devolver um quadro

Novos Cadernos NAEA, v. 16, n. 1, Suplemento, p. 261-280, jun. 2013 
de si mesma redutor, desmerecedor ou mesmo desprezível. Assim, o devido reconhecimento não seria uma mera cortesia que devemos conceder as pessoas, mas sim uma necessidade humana vital. Resulta daí outro fato importante: para compreendermos o estreito vínculo entre identidade e reconhecimento devemos considerar uma característica fundamental da condição humana,

Essa característica crucial da vida humana é seu caráter fundamentalmente dialógico. Tornamo-nos agentes plenos, capazes de nos compreender a nós mesmos e, por conseguinte, de definir nossa identidade, mediante a aquisição de ricas linguagens humanas de expressão. [...] desejo tomar a linguagem em um sentido amplo cobrindo não só as palavras que falamos, mas também outros modos de expressão por meio dos quais nos definimos, incluindo as linguagens da arte, do gesto, do amor etc. (TAYLOR, 2000, p. 246).

Segundo Taylor, as pessoas não adquirem as linguagens que precisam para se autodefinirem por si mesmas. Ao invés disso, adquirimos essas linguagens em constante interação com outras pessoas que têm importância para nós, os outros significativos de que nos fala G.H. Mead. A gênese do espírito humano não é algo que cada pessoa realiza por si mesma, mas o faz dialogicamente. Desta maneira, definimos nossa identidade sempre em diálogo com as coisas que os outros significativos desejam ver em nós e por vezes em luta contra essas coisas. Em outras palavras, a descoberta de minha identidade não implica em uma produção minha, isolada de minha própria identidade; ao contrário, significa que eu a negocio por meio do diálogo, parte aberto, parte interno com os parceiros de interação. Eis porque o desenvolvimento da identidade atribui importância ao reconhecimento. Minha própria identidade depende fundamentalmente de minhas relações dialógicas com os outros.

Para Taylor, a demanda por reconhecimento não é nova, ela já se encontrava presente em épocas anteriores, o que surgiu de novo na modernidade não foi a necessidade de reconhecimento em si, mas as condições em que a tentativa de ser reconhecido pode não se efetivar. No plano teórico, esclarece o autor, a questão do reconhecimento recebe seu primeiro tratamento mais influente em Hegel. A partir daí, a importância do reconhecimento passou a ser universalmente reconhecida de duas formas, no plano intimo e no plano social. No primeiro caso, tornou-se aceito por todos que a identidade pode ser formada ou mal formada no curso de nosso contato com os outros significativos. Podemos ver o quanto uma identidade original precisa do reconhecimento dado ou negado e é vulnerável a eles. No plano social, a compreensão de que as identidades se formam no diálogo aberto fez com que a política do reconhecimento igual 
adquirisse um lugar mais central e de maior peso. Foi desta forma que o discurso do reconhecimento tornou-se familiar a nós tanto no plano da esfera íntima, quanto da esfera pública.

Neste sentido, o processo de consolidação da democracia no Brasil tem ampliado os espaços de participação e de diálogo entre o Estado e a Sociedade Civil e, ao mesmo tempo, contribuído para a criação de espaços e fóruns de debate e de inclusão de novos temas na agenda política, entre eles, as políticas de reconhecimento. Contudo, frequentemente, há uma série de impedimentos estruturais a restringir a entrada dos indivíduos no espaço público ${ }^{2}$. Segundo Fraser (2002), a superação de tais impedimentos, quando advindos da estrutura cultural e/ou simbólica que orienta os padrões de valoração da sociedade, pode acontecer por meio de políticas de reconhecimento que podem, inclusive, implicar na garantia de direitos coletivos.

\section{A PARIDADE PARTICIPATIVA EM CONTEXTOS REIVINDICA- TÓRIOS: NOTAS DE PESQUISA}

Neste tópico passamos a discorrer sobre as os dados obtidos no campo de investigação. Inicialmente faremos uma breve exposição descritiva da região, no que diz respeito à realidade socioeconômica em questão. Após apresentamos a análise dos que foram coletados numa pesquisa que buscou avaliar as condições de vida deste grupo, onde entre as variáveis pesquisadas encontrava-se às condições de participação no contextos das ações do Plano Nacional de Promoção das Cadeias de Produtos da Sociobiodiversidade (PNPSB). Assim, recorreu-se ao método Delphi $i^{3}$ onde aplicados questionários para os atores envolvidos (comunidades agroextrativistas, movimentos sociais e condutores do PNPSB).

De acordo com dados do Censo de 2010, a região do Bico do Papagaio possui uma população estimada em cerca de 110 habitantes, sendo que mais de $60 \%$ estão na zona urbana e os restantes estão na zona rural. O maior município em extensão é Araguatins, que se destaca também na concentração da população na área rural ultrapassando 10 mil habitantes.

A região congrega cerca de 25 mil domicílios, dos quais aproximadamente 11 mil estão também em situação de pobreza, o que representa algo próximo a $45,5 \%$ do total de domicílios, ou $11,3 \%$ dos domicílios pobres em relação do

\footnotetext{
Ver Dagnino (2002).

3 O método Delphi se caracteriza por uma consulta a um grupo de especialistas através de um questionário que é repassado continuadas vezes até que seja obtida uma convergência das respostas. Para um maior detalhamento acerca deste método ver: Wright e Giovinazzo (2000).
}

Novos Cadernos NAEA, v. 16, n. 1, Suplemento, p. 261-280, jun. 2013 
estado, o município de Carrasco Bonito é o que apresenta o maior percentual, de 58,1\% dos domicílios nesta condição (IBGE, 2008).

Diante deste cenário a região tem sido objeto de diversas ações governamentais com intuito desenvolver a região, reduzindo os índices de pobreza e desigualdade social. Nesse contexto, os Ministérios do Desenvolvimento Agrário (MDA), do Desenvolvimento Social e Combate a Fome (MDS) e do Meio Ambiente (MMA), promotores do Plano Nacional de Cadeias de Produtos da Sociobiodiversidade desenvolveram um Plano de Ação Governamental para o desenvolvimento da cadeia de valor do coco babaçu em âmbito nacional, o qual foi estabelecido em conjunto com gestores governamentais e acompanhado pela Casa Civil (BRASIL, 2009).

Com base nos resultados de estudos sobre a cadeia do babaçu, de encontros de discussão e de encaminhamento técnico entre os pontos focais do MDA, MDS, MMA, foram elencadas um conjunto de ações prioritárias, definidos responsáveis e identificados parceiros para a execução do plano de promoção da cadeia produtiva do babaçu (BRASIL, 2009). Em função de um mapa gerado pelo ZEE/MMA, o qual demonstra a interseção entre os municípios que ocorrem o babaçu, com aqueles presentes em Territórios da Cidadania (TC), com a presença de Unidades de Conservação de Uso Sustentável (UCs) ou incluídos na área do Arco Verde, foi determinado que os municípios prioritários para as ações para as ações do Plano seriam aqueles que além de ocorrer o babaçu, coincidissem com algum TC, UCs ou com a área do Arco Verde, e que tenha de média, alta ou muito alta produção de amêndoa, de acordo com os dados do IBGE (2007) relativos à produção do extrativismo não madeireiro.

Apesar de ocorrer em diversos estados, a região apresenta zonas de alta densidade de babaçuais, com populações superiores a 200 palmeiras por hectare. O Babaçu é uma palmeira que atinge cerca de $20 \mathrm{~m}$ de altura, começa a frutificar com 8 a 10 anos de vida, alcançando plena produção aos 15 anos, e tem uma vida média de 35 anos. Produz o ano todo, de 3 a 6 cachos de frutos, cada cacho possui cerca de 150 a 300 cocos e cada coco possui em média 3 amêndoas no seu interior.

As potencialidades do babaçu são inúmeras, da geração de energia ao artesanato, diversas atividades econômicas podem ser desenvolvidas a partir da planta. Dentre as partes desta, o fruto tem o maior potencial econômico para aproveitamento tecnológico e industrial, podendo produzir cerca de 64 produtos, tais como carvão, etanol, metanol, celulose, farináceas, ácidos graxos, glicerina, porém basicamente o carvão e o óleo têm sido produzidos em escala comercial. Apesar da possibilidade de se utilizar o babaçu de diversas formas e em diversos 
processos industriais, é a amêndoa, em função da produção do óleo, que tem a maior importância econômica atualmente.

A grande quantidade de palmeiras na região levou à instalação de várias empresas processadoras de óleo comestível e láurico obtidos a partir da amêndoa do babaçu. "As décadas de 60 ao início de 80 constituíram-se no auge da economia babaçueira. Neste período, 52 empresas de médio e de grande porte funcionavam produzindo óleo bruto e refinado para abastecimento das indústrias alimentícias e de higiene e limpeza no país e no exterior. Entre os empreendimentos dos extrativistas, lista-se aproximadamente 04 cooperativas e 10 associações, as quais processam o mesocarpo com vistas no Programa de Aquisição de Alimentos (PAA), e o óleo bruto de babaçu com fins na exportação para mercados justos e solidários, que chegam a pagar duas a três vezes mais o valor das indústrias produtoras de cosméticos, materiais de higiene e de limpeza instaladas na região sudeste do Brasil, fortes consumidoras de óleo bruto de babaçu.

Toda a produção de amêndoa de babaçu é feita em regime de economia familiar. O babaçu é integralmente aproveitado pelas famílias que sobrevivem da agricultura de subsistência associada à exploração da palmeira. São envolvidos diretamente com a economia do babaçu 400.000 extrativistas (ALMEIDA, 2005), e 1.000.000 de pessoas direta ou indiretamente (PORTO, 2004). Basicamente são mulheres quebradeiras de coco babaçu, que em geral possuem baixo grau de organização da produção, fato que vem gerando grande dependência destas aos atravessadores, os quais chegam a ganhar 40 a 60\% a mais na comercialização da amêndoa.

Apesar do baixo grau de organização da produção e, tendo como interlocutor o Movimento Interestadual das Quebradeiras de Coco Babaçu (MIQCB), uma forte articulação política em prol das demandas apresentadas pelas quebradeiras foi desencadeada em torno da Lei do acesso livre aos babaçuais.Em geral, as mobilizações sociais das quebradeiras de coco podem ser classificadas como mudanças que visam alterar relações sociais excludentes no interior da sociedade. Tendo este conjunto de questões postas, uma das alternativas proposta pelo governo federal para o equacionamento da participação no delineamento das ações referentes s atividade agroextrativista, tem sido as estratégias para compreensão de que princípios mais abrangentes possam direcionar as ações de governo, evitando, assim, a repetição de ações por vezes ineficazes e potencializando todas as iniciativas desenvolvidas pelas comunidades agroextrativistas de babaçu ${ }^{4}$. Abaixo passamos a avaliar os dados obtidos a partir dos questionários aplicados (Figura 1).

Estas ações foram postas em prática a partir do Plano Nacional de Promoção das Cadeias de Produtos da Sociobiodiversidade (PNPSB), que foi a política que subsidiou o Programa Desenvolvimento Sustentável do Território Rural do Bico do Papagaio.

Novos Cadernos NAEA, v. 16, n. 1, Suplemento, p. 261-280, jun. 2013 
Figura 1. Opinião dos painelistas sobre o nível de conhecimento do Plano

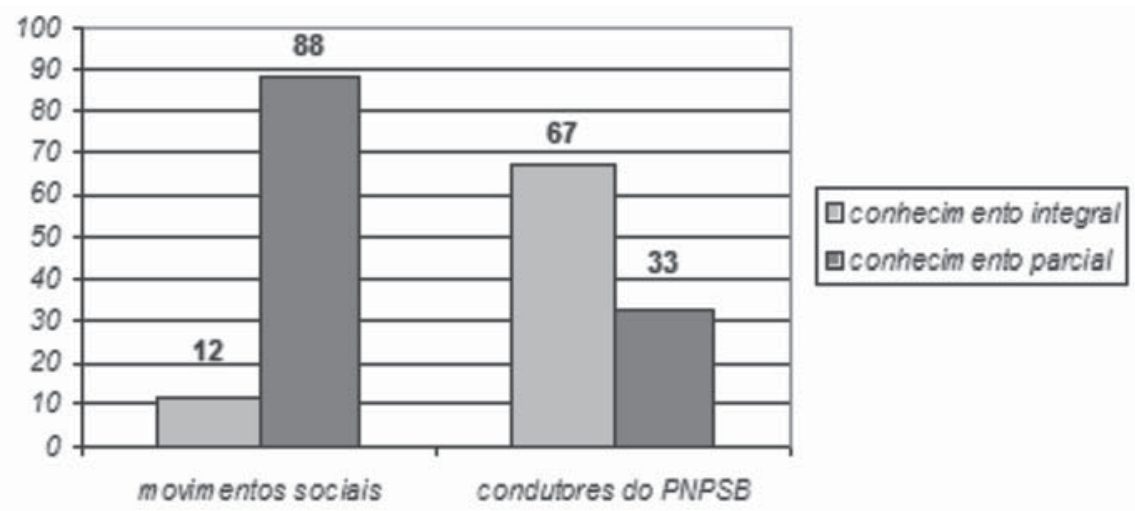

Inicialmente questionamos sobre o nível de conhecimento do Plano 12\% dos painelistas representantes dos movimentos sociais o conhecem integralmente e $88 \%$ conhecem parcialmente. Esta categoria enfatizou a importância da articulação da sociedade civil organizada na implementação de políticas públicas voltadas para comunidades tradicionais, bem como, a conservação dos recursos naturais. E 67\% dos painelistas que representam os condutores dessa política, informaram que o conhecem integralmente e $33 \%$ informaram conhecê-lo parcialmente, onde estes colocaram a necessidade de ampliar a divulgação do Plano para as comunidades mais distantes (Figura 2).

Figura 2. Opinião dos painelistas sobre o objetivo geral do Plano

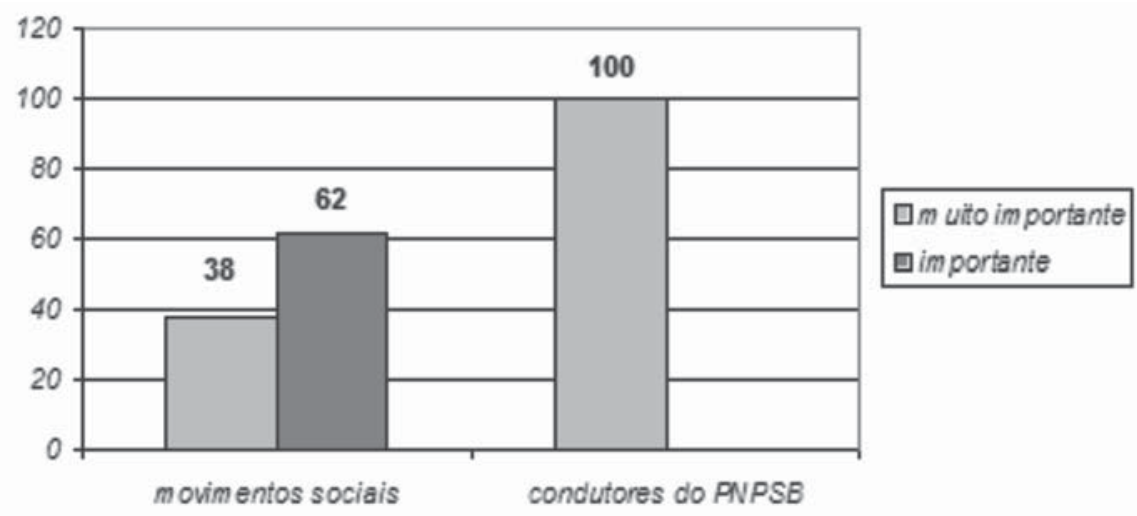

Quanto ao objetivo do Plano, 38\% dos painelistas representantes dos movimentos sociais o consideram muito importante, ao passo que 62\% o consideraram importante. Entretanto, enfatizaram que suas ações precisam de fato se concretizar para que aconteça o fortalecimento do mercado com produtos 
da sociobiodiversidade. E 100\% dos condutores informaram que consideram o Plano, muito importante. De modo geral, considerações em relação aos impactos positivos na qualidade de vida de PCTAFs, ao uso sustentável dos recursos naturais, à consolidação de mercados sustentáveis e à rica diversidade biológica do planeta, foram bastante presentes nos comentários.

Figura 3. Opinião dos painelistas acerca do recebimento de informações sobre a repercussão das ações do Plano junto aos movimentos sociais, comunidades agroextrativistas, ONGs, Instituições Públicas e Privadas.

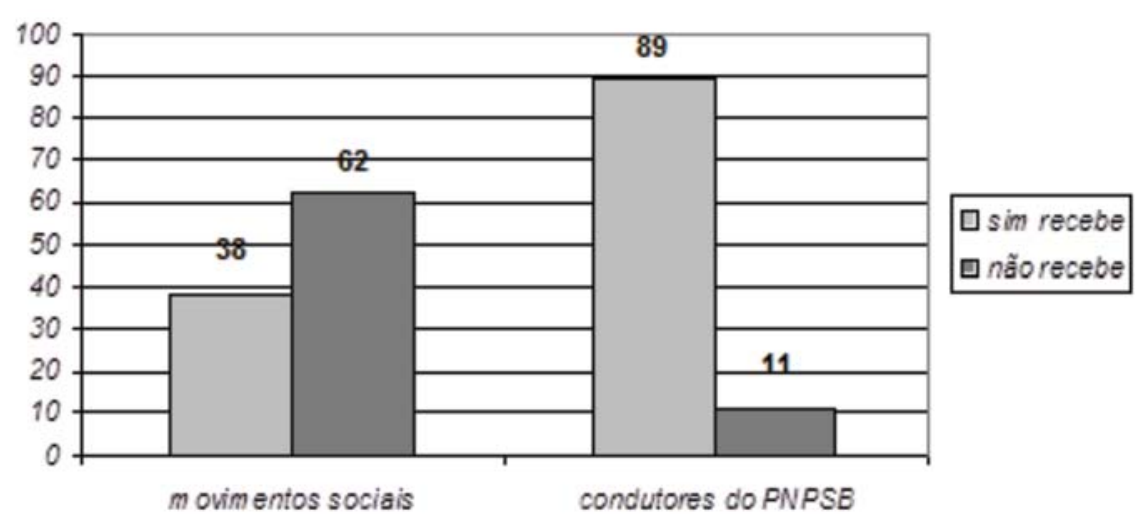

Os representantes dos movimentos sociais apontam um percentual de 38\% em relação ao recebimento de informações sobre as atividades/ações do Plano, enquanto que e $62 \%$ informam que estas informações chegam atrasadas devido ao distanciamento que as políticas públicas têm dos trabalhos das organizações sociais (Figura 3). Por vezes, quando chega a informação sobre um evento o mesmo já aconteceu. $\mathrm{Na}$ opinião dos condutores, 89\% informaram que recebem estas informações, ao passo que 11\% que não recebem informações em suas instituições. Em alguns comentários, reconheceram as dificuldades que algumas organizações sociais têm em acessar essas informações, daí a necessidade de fazer uma divulgação mais abrangente.

A pesquisa apontou que 100\% dos movimentos sociais envolvidos concordam com as diretrizes estabelecidas neste Plano, desde que se concretizem e sejam implementadas de fato (Figuras 4, 5, 6). Do mesmo modo, 100\% dos condutores do PNPSB concordaram com essas diretrizes, alguns lembraram que estas foram definidas com base em seminários regionais e nacional, envolvendo mais de 700 pessoas e tiveram o foco no atendimento às necessidades apresentadas pelas comunidades extrativistas. 
Figura 4. Opinião dos painelistas referente às diretrizes do Plano quanto a atender ou não as necessidades das comunidades extrativistas envolvidas.

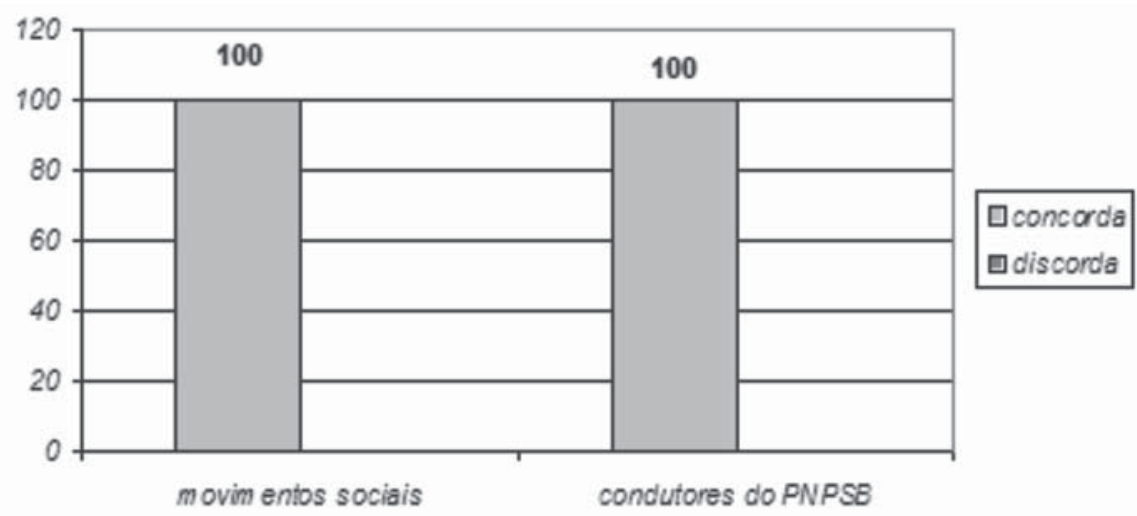

Figura 5. Opinião dos painelistas sobre a execução do Plano num prazo regular.

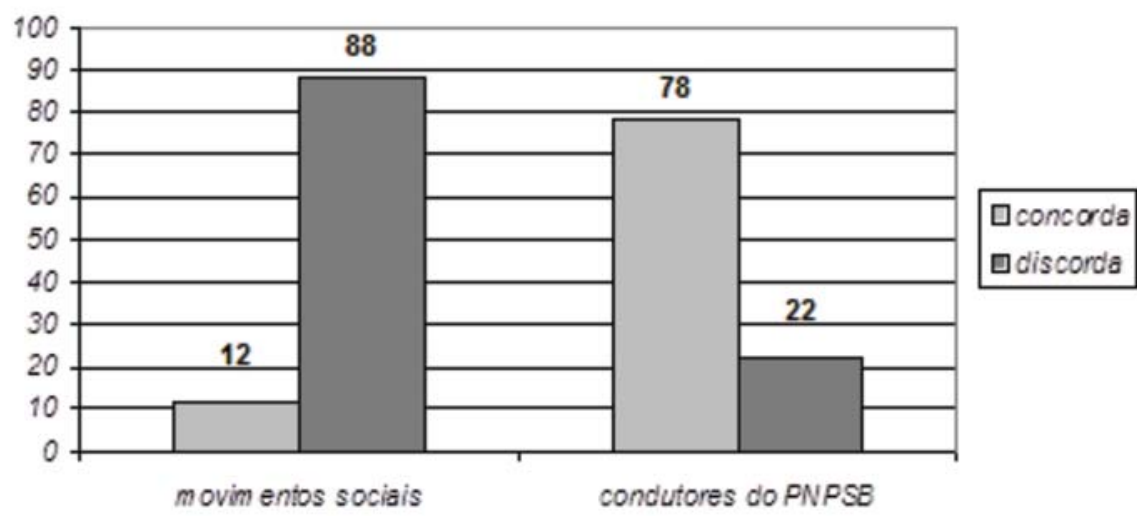

Os resultados obtidos com as organizações sociais apontaram que 12\% concordam com prazo de execução do Plano e $88 \%$ discordam, devido à falta de regularidade nas ações, pois estas nem sempre ocorrem na data planejada e os condutores dessa política demoram bastante tempo para realizá-las. No total de condutores envolvidos, 78\% concordam com o prazo de execução do Plano, e reforçaram que não há prazos determinados para a finalização do Plano de Sociobiodiversidade, que está sendo construído de uma forma contínua e em etapas. Mesmo com esse argumento, 22\% discordaram que o Plano esteja sendo executado dentro do prazo regular, cuja a falta de planejamento de ações num intervalo de tempo menor seria o obstáculo. 
De acordo com os resultados acima, 50\% dos membros de movimentos sociais consideram acessível as informações do site do MDA, mas acrescentam que é também necessário o contato direto com as pessoas responsáveis pela implementação do PNPSB, outros 12\% desconhecem essas informações por meio da internet porque consideram complicado o acesso, ao passo que 38\% informaram que nas suas comunidades não chegou internet (Figura 6).

Figura 6. Opinião dos painelistas relacionada à disponibilidade das informações do Plano no Portal da Comunidade da Sociobiodiversidade/MDA.

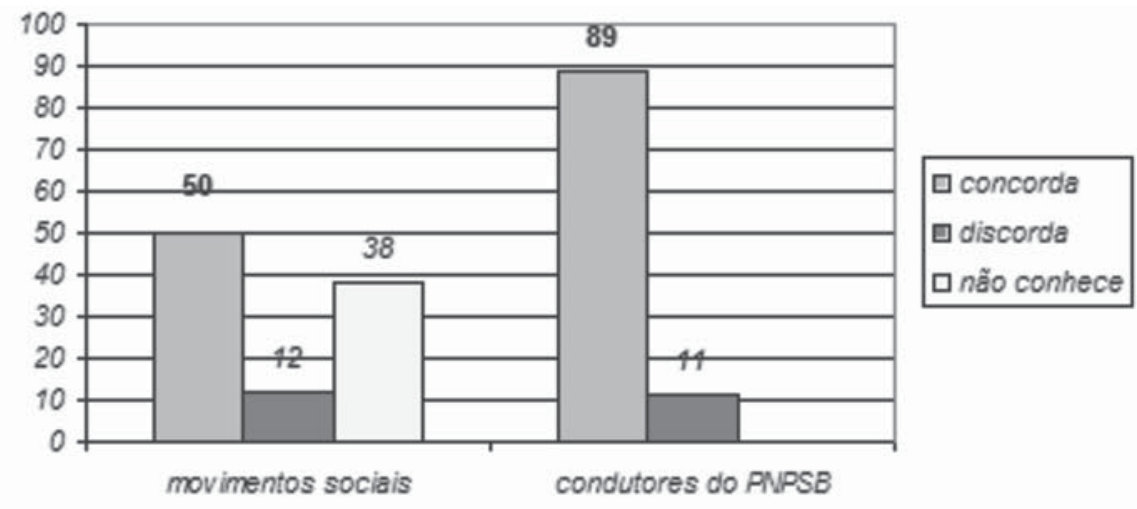

No resultado dos condutores do Plano 89\% consideram acessíveis as informações do site do MDA, mas enfatizaram que muitas organizações de base ainda não possuem acesso à internet, onde seria oportuno e fundamental criar outro instrumento mais popular com uma linguagem mais acessível para essas comunidades, enquanto que 11\% discordam da acessibilidade das informações no site do MDA.

Os movimentos sociais apontam para um resultado no qual 38\% concordam com o fato da localização remota dificultar o desenvolvimento desses projetos, ressaltando que muitas vezes o produto fica armazenado e perde a validade, isso ocorre devido ao acesso ruim e à distância (Figura 7). Porém, 62\% dessas organizações discordam que a localização remota de uma comunidade possa representar um empecilho ao avanço de projetos que aproveitem em maior escala o coco de babaçu, e ainda consideram as questões burocráticas o principal obstáculo encontrado para inserir os produtos da agricultura familiar no mercado.

O total de condutores do Plano envolvidos nessa pesquisa indica que $56 \%$ consideram um entrave a localização distante de algumas comunidades extrativistas de babaçu, e destacam que a partir do processo de organização das comunidades e de políticas públicas voltadas para o setor essas dificuldades serão dirimidas, e os projetos serão realizados com eficácia. Outros 44\% discordam dos 
demais, destacando que a falta de uma estratégia logística organizada, favorece a inserção de atravessadores na cadeia produtiva e isso dificulta a melhoria dos ganhos dos extrativistas, mas esse é um impedimento que pode ser diminuído se as condições de infra-estrutura e de logística forem planejadas através de políticas públicas ou parcerias, que seriam, por hipótese, estabelecidas com o setor privado. Neste contexto, a distância dificulta a comercialização e encarece alguns custos, porém existem boas estradas no Bico do Papagaio, constatando-se, assim, que e o problema maior das comunidades extrativistas que trabalham com o coco de babaçu é, de fato, a falta de transporte e a logística.

Figura 7. Opinião dos painelistas sobre a localização remota de várias comunidades extrativistas de babaçu, considerada como impedimento para os projetos com estes produtos.

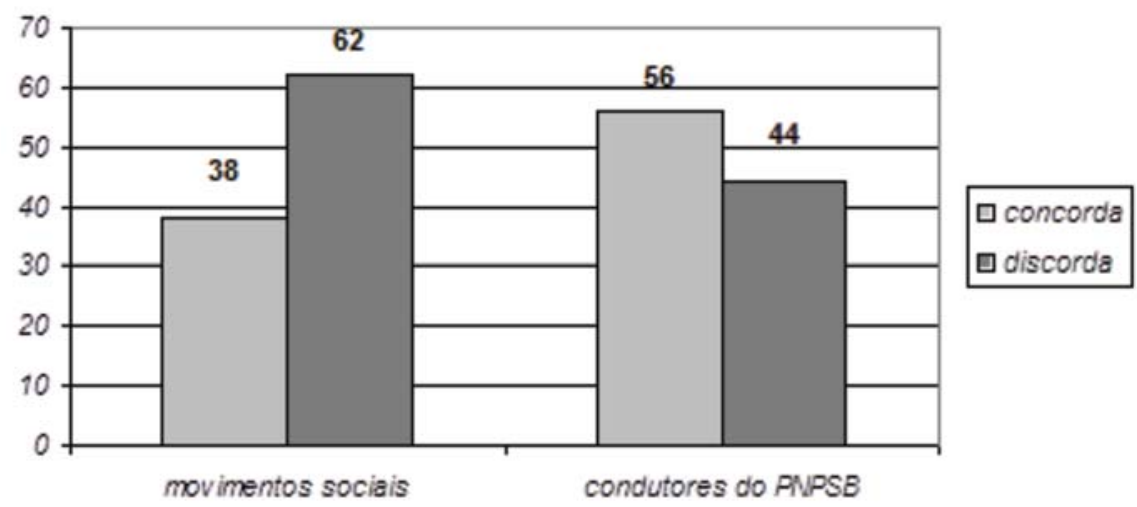

Em 88\% das respostas de movimentos sociais, as elevadas taxas de analfabetismo são obstáculos na gestão dos empreendimento estabelecidos com o babaçu, além de seus membros (quebradeiras) revelarem as dificuldades que tiveram para educar os filhos mais velhos, bem como, o impedimento que existe, por parte delas, no momento de realizar os cálculos para saber o resultado da comercialização de seus produtos (óleo, amêndoa, carvão). Outras $12 \%$ responderam que discordam da situação de que as das elevadas taxas de analfabetismo impedem o desenvolvimento na gestão de micro projetos e empreendimentos voltados ao aproveitamento do babaçu (Figura 8).

No total de condutores envolvidos as respostas indicam que 89\% concordam que as elevadas taxas de analfabetismo impedem o bom desempenho nos referidos empreendimentos. Algumas considerações ressaltam o analfabetismo como um obstáculo para diversas atividades, daí a necessidade dos jovens terem acesso a uma escola que lhes permita outras escolhas como as 
Casas Familiares Rurais ou Escolas Família Agrícola. Nas demais respostas, 11\% dos demais painelistas afirmaram discordarem de que essa situação é gerada pelas elevadas taxas de analfabetismo.

Os movimentos sociais revelaram bastante interesse na articulação entre o PAA e o PNPSB, pois 100\% destes acreditam que através da articulação dessas duas políticas poderão ampliar as oportunidades de mercado para os produtos do coco de babaçu (Figura 9). Enfatizaram que por meio da comercialização praticada com o apoio de recurso do PAA, os frutos não se desperdiçam e nem os produtos perdem a validade, além de comercializarem entre si, com as outras companheiras.

Figura 8. Opinião dos painelistas referente às elevadas taxas de analfabetismo, consideradas como obstáculo na gestão de empreendimentos com produtos da sociobiodiversidade.

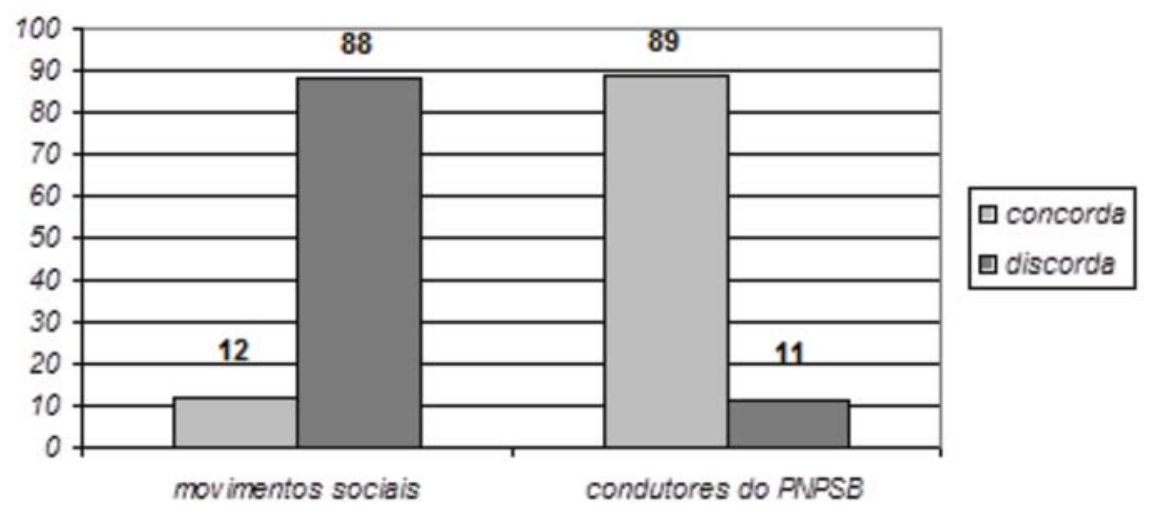

Gráfico 09. Opinião dos painelistas sobre á utilização do PAA (Programa de Aquisição de Alimentos da Agricultura Familiar) como mecanismo para ampliar o mercado de produtos e subprodutos do babaçu.

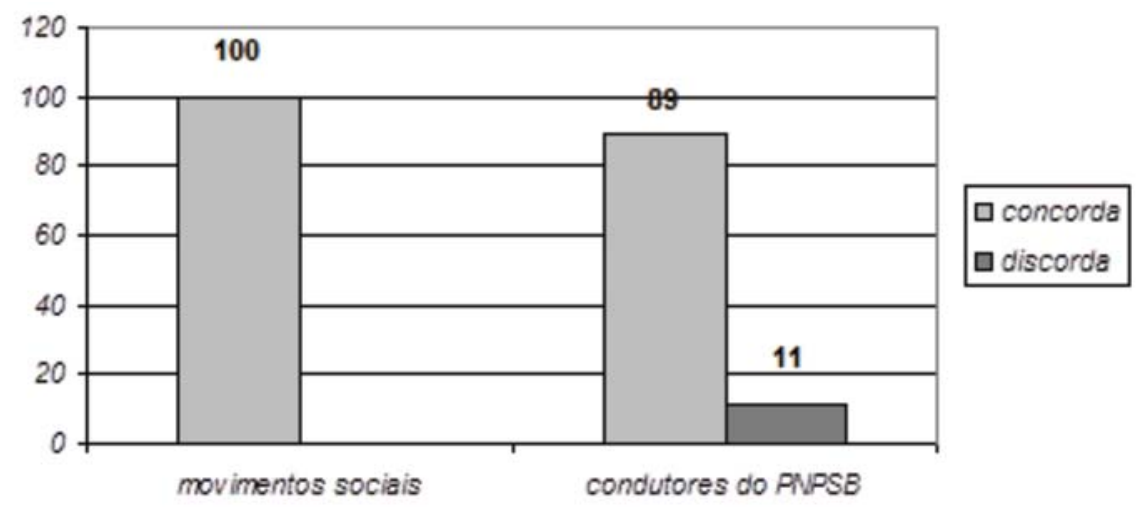

Novos Cadernos NAEA, v. 16, n. 1, Suplemento, p. 261-280, jun. 2013 
As respostas dos condutores envolvidos indicaram 89\% concordando com esse mecanismo, acrescentando que o acesso às políticas públicas de apoio à comercialização é o primeiro passo para a inclusão social que e precisa ser estimulado. Contudo, 11\% dos demais painelistas discordaram das possibilidades advindas desse mecanismo.

Nas respostas adquiridas com os movimentos sociais, $88 \%$ concordam com as ações descritas para estruturar o processamento do coco de babaçu (Figura 10). No entanto, ressaltam que além do interesse nas inovações tecnológicas o objetivo maior é de manter as tradições culturais, pois dessa forma estarão garantindo a valorização de sua categoria. $\mathrm{Na}$ oportunidade, reafirmaram as dificuldades em conseguir certificação, selos e notas fiscais. Outros 12\% discordam dessas ações, sem nada a ponderar.

Figura 10 - Opinião dos painelistas referente às ações para o fortalecimento do processo de industrialização do coco de babaçu.

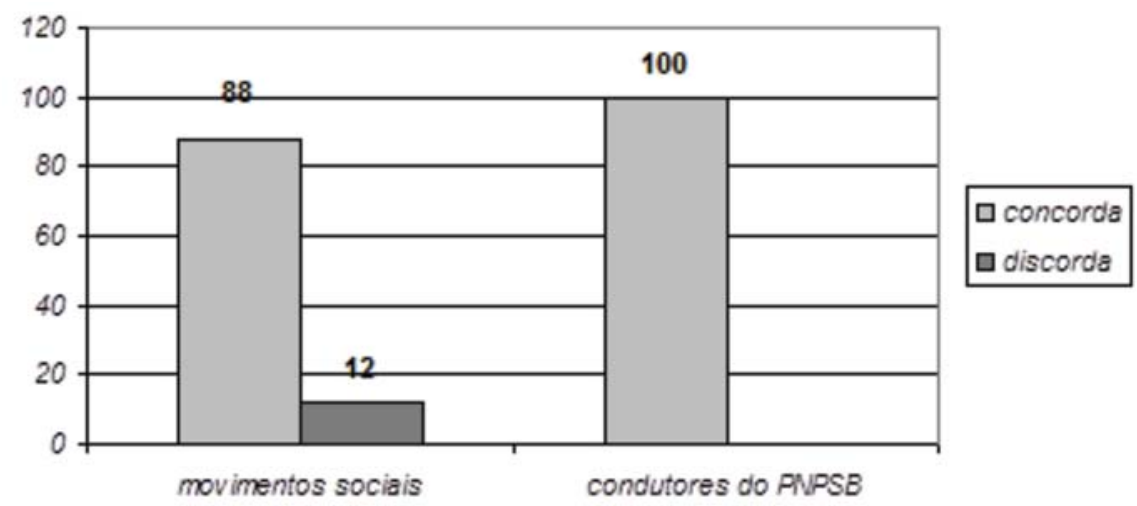

\section{CONSIDERAÇÕES FINAIS}

Observou-se no desenvolvimento deste trabalho que existe um amplo campo de reivindicações no âmbito laboral e cultural das quebradeiras. Contudo, observa-se que que estas reivindicações são conflitivas, pois, relacionam-se a interesses diversos e no maioria das vezes antagônicos, quando comparados com os interesses de outros grupos. As dificuldades de acesso e compreensão do conjunto de informações disponibilizado processos públicos acabam por gerar situações que deslegitimam estes atores, uma vez que tais atores passam a carecer de informações e conhecimentos que os possibilitem a participar das 
decisões com igualdade de conhecimentos sobre as estruturas e os meandros dos processos postos em prática pela burocracia estatal. Por outro lado, as dificuldades econômicas que se expressam, entre outras, na dificuldade para a participação em diversos momentos de reuniões, encontros, etc., faz com que estes atores participem de forma descontinuada dos debates. Tal fato acaba por facilitar a ação de outros atores que possuem interesses em influenciar o processo de condução da política pública no que que se refere às suas metas e objetivos.

Em suma, tem-se observado que, em situações de paridade participativa, as quebradeiras carecem de uma apropriação econômica e de meios econômicos que possibilite a independência e a voz em debates públicos, ao mesmo tempo em que suas reivindicações em relação ao Babaçu Livre não são reconhecidas como plenamente legítimas, uma vez que fere o direito de propriedade daqueles que possuem os títulos das terras. Tal estratégia acaba por desqualificar as demandas deste grupo, quando em embates na esfera pública. O que se observa, de fato, é que o enfrentamento da condição de não paridade tem se constituído num verdadeiro óbice no estabelecimento de diálogos que este grupo tem estabelecido em torno da questão.

No plano teórico, Fraser (2001) tem proposto algumas ações capazes de superar dificuldades como as apresentadas pelas ações afirmativas. Trata-se das ações transformativas. No plano cultural, as ações transformativas encontram-se atualmente associadas à desconstrução. Elas reparariam o desrespeito por meio da transformação da estrutura cultural-valorativa que serve de pano de fundo. Pela desestabilização das identidades e diferenciações de grupos existentes, essas ações têm o potencial de elevar a auto-estima dos integrantes dos grupos e ao mesmo tempo mudar a percepção de todos sobre a individualidade. No plano econômico, as ações transformativas buscam rever distribuições injustas por meio de transformação das estruturas político-econômicas. Pela reestruturação das relações de produção essas ações não só alterariam a distribuição estatal de bens de consumo, mas também mudariam a divisão social do trabalho e assim as condições existenciais de todos (Fraser, 2001). Trata-se, portanto, de um processo aberto a novas considerações.

Novos Cadernos NAEA, v. 16, n. 1, Suplemento, p. 261-280, jun. 2013 


\section{REFERÊNCIAS}

BRASIL. Ministério do DesenvolvimentoAgrário, Ministério do Desenvolvimento Social e Combate à Fome e Ministério do Meio Ambiente. Promoção Nacional da Cadeia de Valor do Coco Babaçu. Brasília, 2009. Disponível em: www. mda.gov.br/portal/saf/arquivos/.../Plano_Ação_Cadeia_Babaçu.pdf. Acesso em: 10 set. 2012.

COSTA, S. Reconhecer as diferenças: liberais comunitaristas e as relações raciais no Brasil. In: AVRITZER, L.; DOMINGUES, J. M. (Orgs.). Teoria social e modernidade no Brasil. Belo Horizonte: UFMG, 2000.

DAGNINO, E. Sociedade civil e espaços públicos no Brasil. São Paulo: Paz e Terra, 2002.

FRASER, N. HONNETH, A. ¿Redistribuición o reconocimiento? Madrid: Morata, 2006.

FRASER, N. A justiça social na globalização: Redistribuição, reconhecimento e participação. Coimbra: Revista Crítica de Ciências Sociais, 2002. Disponível em: http://www.ces.uc.pt/publicacoes/rccs/063/063.php. Acesso em: 25out. 2006.

póssocialista.

- Da redistribuição ao reconhecimento? dilemas da justiça na era

In: SOUZA, J. Democracia hoje: novos desafios para a teoria democrática contemporânea. Brasília: EDUNB, 2001.

. La justicia social em la era de la política de la identidad: redistribuicion, reconocimento y participación. In: FRASER, N. HONNETH, A. ¿ Redistribuición o reconocimiento? Madrid: Morata, 2006.

HABERMAS, J. A política de reconhecimento. In: TAYLOR, C. Multiculturalismo examinando a política de reconhecimento. Lisboa: Instituto Piaget, 1998.

A inclusão do outro: estudos de teoria política. 2. ed. São Paulo: Loyola, 2004.

KRISCHKE, P. Governo Lula: políticas de reconhecimento e de redistribuição. Florianópolis: PPGICH-UFSC, 2003. (Cadernos de Pesquisa Interdisciplinar).

Democratização cultural e políticas de reconhecimento: notas sobre a trajetória do partido dos trabalhadores (PT). Interthesis, PPGICHUFSC. Disponível em: <http://www.interthesis.cfh.ufsc.br/interthesis3/artigo2.pdf $>$.Acesso: em 07 nov. 10 . 
MEAD, G.H. Espiritu, persona y sociedad: desde el punto de vista del conductismo social. Buenos Aires: Editorial Paidos, [s.d.].

NEVES, P. S. C. Luta anti-racista: entre reconhecimento e redistribuição. Revista Brasileira de Ciências Sociais, v. 20, n. 59. out. 2005.

OGANDO, A. C.; ASSIS, M. P. F. Reconhecimento e direitos individuias: categorias em tensão e o caso das mulheres brasileiras. Disponível em: http:// www.fazendogenero7.ufsc.br/artigos/O/Ogando-Assis_34.pdf . Acesso em: 17 out. 2010 .

SILVA, J. P. Teoria Crítica na Modernidade Tardia: sobre a relação entre redistribuição e reconhecimento. In: ENCONTRO ANUAL DA ANPOCS, 29. 2005. Caxambu. Anais... Caxambu: ANPOCS, 2005.

Cidadania e reconhecimento. In: AVRITZER, L.; DOMINGUES, J. M. (Orgs.). Teoria social e modernidade no Brasil. Belo Horizonte: UFMG, 2000.

SOUZA, J. A gramática social da desigualdade brasileira. Revista de Ciências Sociais, v.54, 2004.

- Democracia hoje: novos desafios para a teoria democrática contemporânea. Brasília: EDUNB, 2001.

SPOSATI, A. Especialidade e intersetorialidade da política de assistência social. Serviço Social e Sociedade, São Paulo, n. 77, p.30-53. mar. 2004.

TAYLOR, C. Multiculturalismo examinando a política de reconhecimento. Lisboa: Instituto Piaget, 1998.

Argumentos fi losófi cos. São Paulo: Loyola, 2000.

WRIGHT, J. T. C.; GIOVINAZZO, R. A. Delphi: uma ferramenta de apoio ao planejamento prospectivo. Caderno de pesquisas em Administração, São Paulo, v. 1, n. 12, p. 54-65, 2000. 